\title{
Analysis of Roll Equivalent Crown of CVC-6h Mill
}

\author{
YANG Guang-hui ${ }^{1,}$ a, ZHANG Jie ${ }^{1}$, CAO Jian-guo ${ }^{1}$, XIE Zhen-ning ${ }^{1}$ \\ ${ }^{1}$ School of Mechanical Engineering, University of Science and Technology Beijing, Beijing 100083, \\ China. \\ ayanggh@ustb.edu.cn
}

Keywords: tandem cold rolling mill, finite element model, limit specification, shape control, roll equivalent crown

Abstract. The $2180 \mathrm{~mm}$ tandem cold rolling mill is one of the widest cold mills in the world, and it improves the output and production efficiency largely, but some problems puzzle the production such as shape problems of strip, especially the limit width specification. In order to solve the problems, it is necessary to redesign the intermediate roll contour. However, the $2180 \mathrm{~mm}$ mill is a six-roll mill, and the intermediate roll adopts CVC contours, and the strip does not contact the CVC contour directly. The roll equivalent crown of the CVC contour can not be used after calculation. It is necessary to study the corresponding relationship between roll equivalent crown and strip crown of the ultra-wide mill. The finite element simulation model (FEM) is built with the MSC.Marc software. Through using the model, the corresponding relationship between roll equivalent crown and strip crown is analyzed, the result shows that the needed crown of work roll is the minimum, however, the needed crown of backup roll is the maximum in order to roll the strip which is same strip crown and approximate same cross section shape, and the effect of roll crown used in different rolls exists a relationship between each other.

\section{Introduction}

Since China has introduced the first set mill-the $1700 \mathrm{~mm}$ cold rolling mill on the seventy's of last century, the shape technologies such as rapid roll bending, CVC(Continuously Variable Crown), HC(High Crown), PC(Pair Cross), laminar cooling and so on have been widely used in wide-strip-steel tandem cold rolling mill. The common product width of cold rolling is generally below $1800 \mathrm{~mm}$, the ratio of width to thickness is not more than 3800. In recent years, the number of ultra-wide rolling mill increases day by day, and the rolling width is greater than the $1800 \mathrm{~mm}$, and the ratio of width to thickness already reaches 4000 , which brings a lot of difficulties to the shape control of strip ${ }^{[1-10]}$.

The rolling width and roll length of the ultra-wide rolling mill are increased significantly, but the rolling thickness of strip and roll diameter do not change much. The increase of the width to thickness ratio of steel strip is easier to buckle, particularly prone to complex wave, and the large length to diameter ratio of the roll is easier to bend, this undoubtedly increases the difficulty of shape control of super wide strip mill. The 2180 $\mathrm{mm}$ rolling mill can roll the maximum width of $2080 \mathrm{~mm}$, and it is equipped with many shape control means such as work roll and intermediate roll bending force, intermediate roll shifting and laminar cooling.

The work roll of a CVC four-roll mill adopts CVC contours, the strip contacts the CVC contour directly, and its roll equivalent crown is easier to calculate. However, the $2180 \mathrm{~mm}$ mill is a six-roll mill, and the intermediate roll adopts CVC contours, and the strip does not contact the CVC contour directly. The roll equivalent crown of the CVC contour cannot be used after calculation. It is necessary to study the corresponding relationship between roll equivalent crown and strip crown of the ultra-wide mill.

\section{Establishment of finite element model}

The Finite element model including roll and strip is built with the MSC.Marc software, and its modelling parameters are shown in Table 1 and Table 2, and its model is shown in Figure 1(a ${ }^{[11-15]}$. Because the CVC mill has dissymmetry contour of intermediate roll, it needs to establish the section model of the upper and lower roll system. The model adopts the integration form including elastic deformation of roll and plastic deformation of strip, and its advantage is that it avoids the distribution assumption of deformation resistance 
of strip, meanwhile, it can apply the rear tension on the strip, so it is more suitable for the actual rolling process.

Table 1. Geometrical parameters of finite element simulation model

\begin{tabular}{c|c|c}
\hline Roll & Roll barrel(diameter $\times$ length $)$ & Roll neck(diameter $\times$ length $)$ \\
\hline Work roll $(\mathrm{mm} \times \mathrm{mm})$ & $520 \times 2180$ & $317.5 \times 250+465 \times 360$ \\
\hline Intermediate roll $/(\mathrm{mm} \times \mathrm{mm})$ & $610 \times 2580$ & $355.6 \times 266+565 \times 164$ \\
\hline Backup roll $(\mathrm{mm} \times \mathrm{mm})$ & $1380 \times 2140$ & $900 \times 1051$ \\
\hline Strip $/(\mathrm{mm} \times \mathrm{mm})$ & $1000 \sim 2000 \times 0.5 \sim 5($ width $\times$ thickness $) \sigma_{s}=270 \mathrm{MPa}, \sigma_{b}=320 \mathrm{MPa}$ \\
\hline
\end{tabular}

Table 2. Rolling parameters of finite element simulation model

\begin{tabular}{c|c}
\hline Parameter & Value \\
\hline Unit rolling force $/\left(\mathrm{kN} \cdot \mathrm{mm}^{-1}\right)$ & 10 \\
\hline Bending force of work roll/kN & $-350 \sim 500$ \\
\hline Shifting stroke $/ \mathrm{mm}$ & $-200 \sim 200$ \\
\hline Tension $/ \mathrm{kN}$ & 0 \\
\hline Bending force of intermediate roll/ $/ \mathrm{kN}$ & $-450 \sim 650$ \\
\hline
\end{tabular}

The model unit selects 8 node tetrahedral element, and it has a total of 16258 units, 22626 nodes. The contact units are refined in the regions between rolls and between roll and strip as shown in Figure 1(b). The CVC contour of intermediate roll as shown in Figure 2 can be input by the coordinate value.

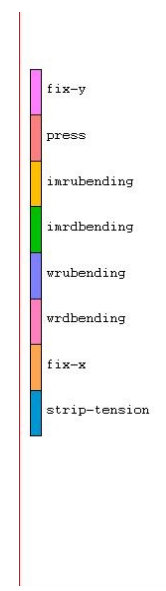

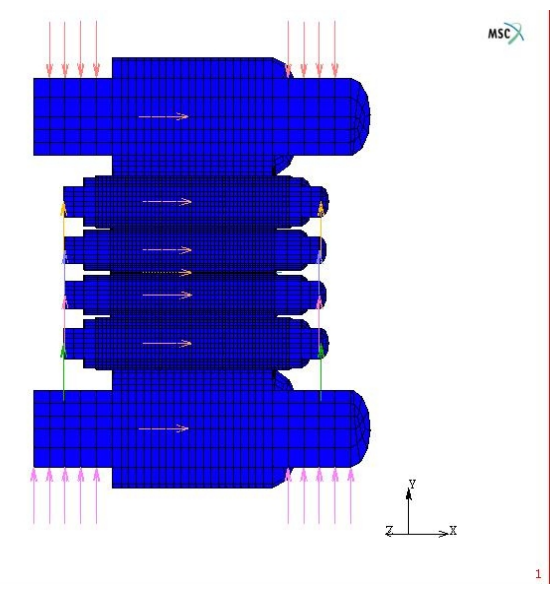

(a)

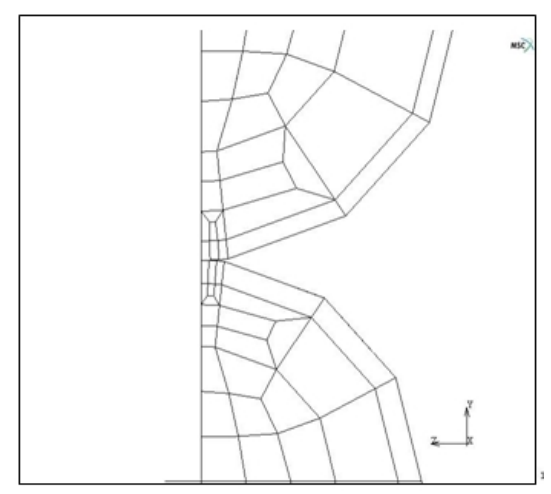

(b)

Figure 1. Finite element model including roll and strip

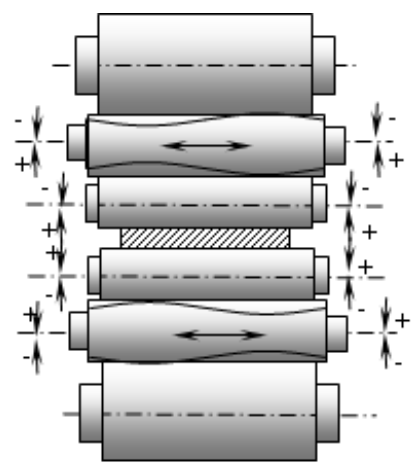

Figure 2. Sketch map of six-roll mill 


\section{Corresponding relationship between roll equivalent crown and strip crown}

Due to the increase of the number of roll of six-roll mill, makes the mill, especially the optimization of roll shape have more choices, however, whether the impacts that the same crown (or equivalent crown) is used in different roll on the rolled strip are the same or not, in order to solve this problem, need the application analysis on the equivalent degree problem of roll shape.

On the assumption that the work roll, intermediate roll and backup roll are all conventional crown rolls, the strip crown and cross section are calculated and analyzed in different roll crown. The roll crowns are respectively 0, 0.02, 0.04, 0.06 and $0.08 \mathrm{~mm}$ as shown in Table 3. Except for the considered roll, the roll contours of the rest are flat.

Table 3. Corresponding relationship between strip crown and roll crown

\begin{tabular}{c|c|c|c|c|c}
\hline Roll crown $/ \mathrm{mm}$ & 0 & 0.02 & 0.04 & 0.06 & 0.08 \\
\hline $\begin{array}{c}\text { Srtip crown of different work } \\
\text { roll crown } / \mathrm{mm}\end{array}$ & 0.16993 & 0.160921 & 0.151518 & 0.142674 & 0.13431 \\
\hline $\begin{array}{c}\text { Srtip crown of different } \\
\text { intermediate roll crown } / \mathrm{mm}\end{array}$ & 0.16993 & 0.164409 & 0.159057 & 0.15299 & 0.147508 \\
\hline $\begin{array}{c}\text { Srtip crown of different } \\
\text { backup roll crown } / \mathrm{mm}\end{array}$ & 0.16993 & 0.167701 & 0.165726 & 0.163616 & 0.161571 \\
\hline
\end{tabular}

The variation corresponding relationship between roll crown and strip crown is described in curve as shown in Figure 3, strip crown changes with roll crown in a linear change, and the change rate of backup roll is the minimum, and the change rate of work roll is the maximum. The change rates of work roll, intermediate roll and backup roll are respectively $0.045,0.028$ and 0.0104 . It can be seen from the Figure 3, although the rolling effects that the same roll contour is used for the different rolls are not completely equivalent, but there are certain relationships.

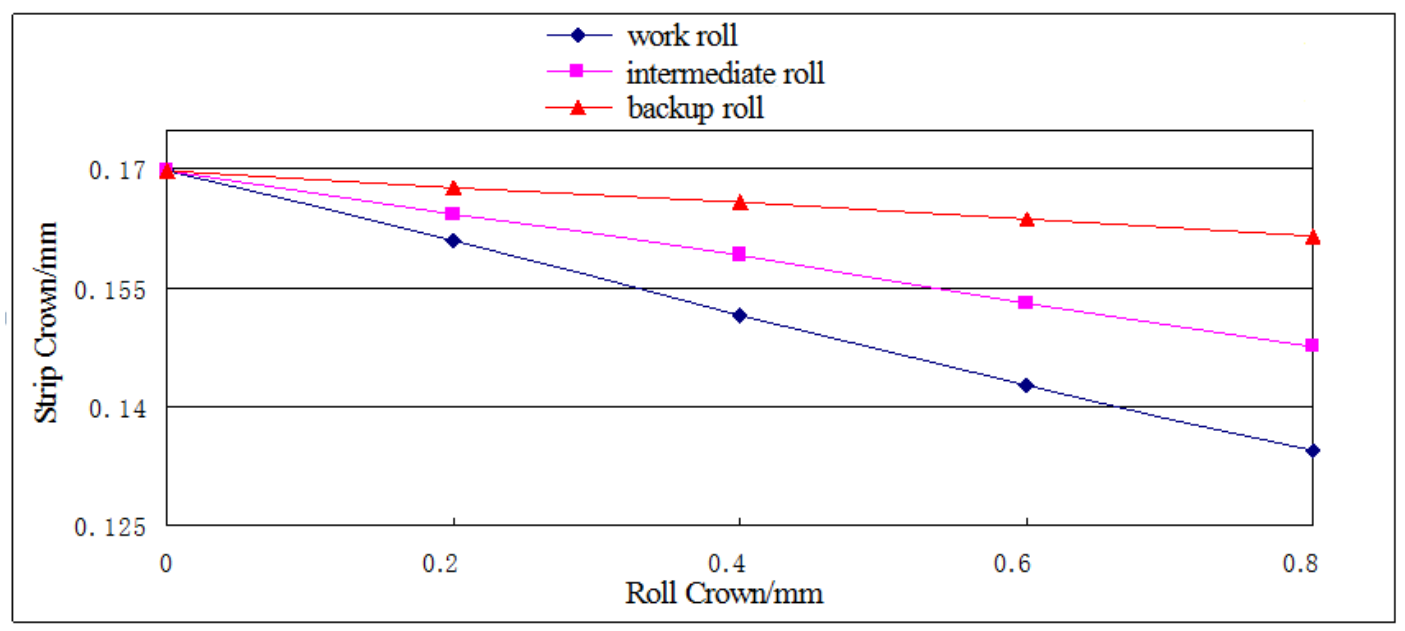

Figure 3. Corresponding relationship between roll equivalent crown and strip crown

\section{Comparison of strip cross section shape}

Select No.1 group and No.2 group of work roll, intermediate roll and backup roll with which the crowns of the rolled strip are the same, wherein, the crown of work roll of the No.1 group is $0.08 \mathrm{~mm}$, and the crowns of intermediate roll and backup roll are flat. The crown of backup roll of the No. 2 group is $0.02 \mathrm{~mm}$, and the crowns of work roll and intermediate roll are flat. Their difference of cross sections is shown in Figure 4.

Select No.3 group and No.4 group of work roll, intermediate roll and backup roll with which the crowns of the rolled strip are the same, wherein, the crown of intermediate roll of the No. 3 group is $0.06 \mathrm{~mm}$, and the crowns of work roll and backup roll are flat. The crown of backup roll of the No.4 group is $0.02 \mathrm{~mm}$, and the crowns of work roll and intermediate roll are flat. Their difference of cross sections is shown in Figure 5. 
Select No.5 group and No.6 group of work roll, intermediate roll and backup roll with which the crowns of the rolled strip are the same, wherein, the crown of work roll of the No.5 group is $0.04 \mathrm{~mm}$, and the crowns of intermediate roll and backup roll are flat. The crown of intermediate roll of the No.6 group is $0.02 \mathrm{~mm}$, and the crowns of work roll and backup roll are flat. Their difference of cross sections is shown in Figure 6.

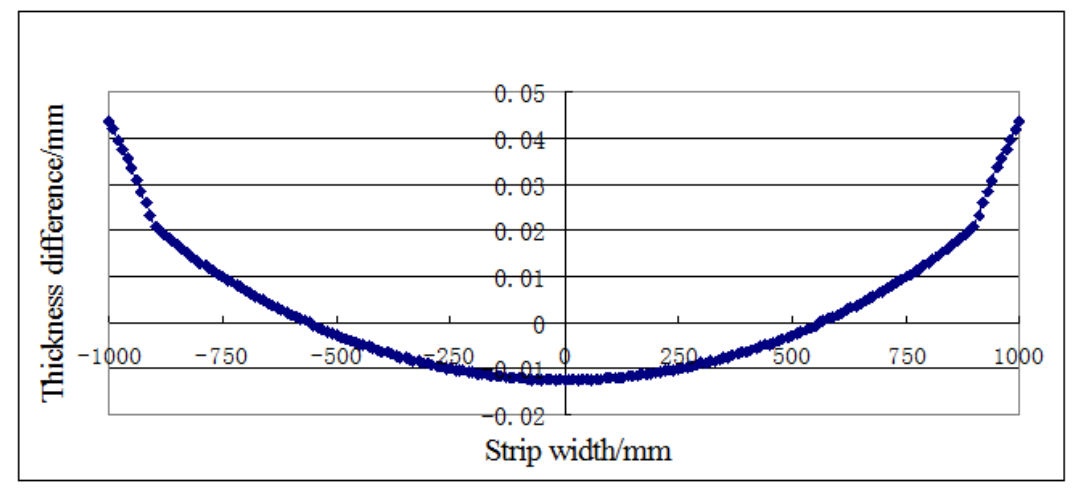

Figure 4. Difference of cross sections of No.1 group and No.2 group

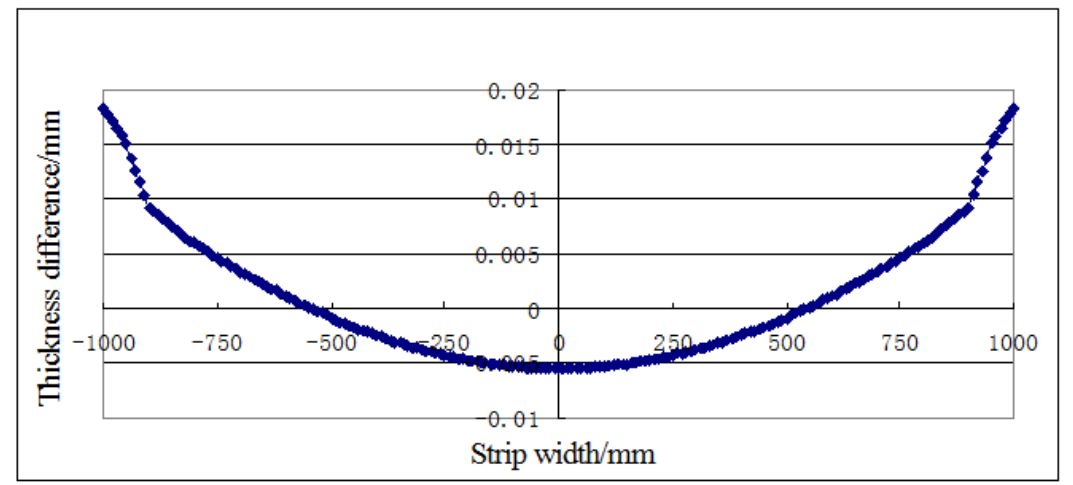

Figure 5. Difference of cross sections of No.3 group and No.4 group

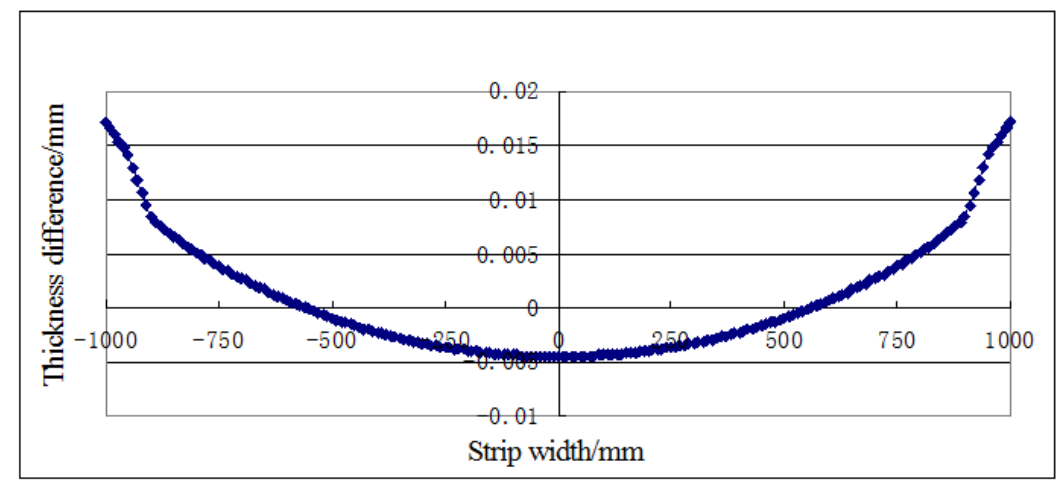

Figure 6. Difference of cross sections of No.5 group and No.6 group

It is seen from that Figure $4 \sim$ Figure 6 that differences of all cross section shape of strips are within $0.06 \mathrm{~mm}$, taking the rolled strip thickness $5 \mathrm{~mm}$ into account, so it can be thought that the cross section shapes of all rolled strips are almost the same corresponding to these roll crowns.

\section{Summary}

To sum up, if using different crown rolls to roll the strip respectively, in order to roll the strip which is the same strip crown and approximate same cross section shape, the needed crown of work roll is the minimum, however, the needed crown of backup roll is the maximum, and the effect of roll crown used 
in different rolls exists a relationship between each other. So the crown roll contour can be selected to use on work roll, intermediate roll or backup roll according to the actual produciton. For example, the $\mathrm{CVC}$ mill can use the roll crown contour on the intermediate roll, and the $\mathrm{HC}$ mill can be use the roll crown contour on the work roll.

\section{Acknowledgements}

This work was funded by the Fundamental Research Funds for the Central Universities (FRF-TP-14-033A2) and the Beijing Higher Education Young Elite Teacher Project (No.YETP0369).

\section{References}

[1] Qian Weichang, Ye Kaiyuan. Elastic mechanics [M]. Beijing: Science Press, 1980.

[2] Yang Guanghui, Cao Jianguo, Zhang Jie, et al. Profile and flatness control technology with a long shifting stroke on wide non-oriented electrical steel sheets [J]. Journal of Iron and Steel Research International, 2012, 19(1): 31-35.

[3] F.D. Fischer, F.G. Rammerstorfer, et al. Buckling phenomena related to rolling and leveling of sheet metal [J]. International Journal of Mechanical Science, 2000(42): 1887-1910.

[4] YANG Guanghui, LI Yuqi, GAO Yang. Finite element analysis of shape control for continuous hot rolling mills of super wide strip steel [J]. Computer Aided Drafting, Design and Manufacturing (CADDM), 2013, 23(1): 79-83.

[5] Ginzburg V B, Azzam M. Selection of optimum strip profiles and flatness technology for rolling mills [J]. Iron and Steel Engineer, 1997, 32(7): 30 38.

[6] A.Seilinger, A.Mayrhofer, A.Kainz. SmartCrown - A new system for improved profile \& flatness control in strip mills [J]. Steel Times International, 2002, 11: 11.

[7] Chen Xanlin, Yang Quan, Zhang Qingdong, et al. Varying contact back-up roll for improved strip flatness $[\mathrm{C}] / /$ Steel Technology International, Sterling Publications Limited, London, 1994/1995(yearly): 174 178.

[8] Yan Qintai. Study on shape control characteristics for super-wide-strip tandem cold rolling mills [D]. Beijing: University of Science and Technology, Beijing, 2010 (in Chinese).

[9] Chang Tiezhu, Zhang Qingdong, Hang Shiqing. Analysis of transverse buckling for thin strip [J]. Chinese Mechanical Engineering, 2009, 20(18): 2255-2259.

[10] F.G. Rammerstorfer, et al. Buckling of free infinite strips under residual stresses and global tension [J]. Journal of Applied Mechanics, 2001(68): 399-404.

[11] YANG Quan, CHEN Xian-Lin, XU Yao-huan, et al. Applying VCL backup roll to raise the control level of strip shape [J]. Iron and Steel, 1995, 30(2): 48-51 (in Chinese).

[12] Yang Quan, Chen Xianlin. The deforming route of buckled waves of rolled strip [J]. International Journal of Mechanical Science, 2000, 16(1): 53-57.

[13] CAO Jian-guo, ZHANG Jie, CHEN Xian-Lin, et al. Selection of mill type configuration for profile and flatness control of tandem cold rolling Mill [J]. Journal of University Science and Technology Beijing, 2003, 23(S3): 109-112 (in Chinese).

[14] CHEN Jun-ping, YANG Guang-hui, YANG Bin. Finite element analysis of steam turbine diaphragm [J]. Computer Aided Drafting, Design and Manufacturing (CADDM), 2014, 24(4): 60-63.

[15] YANG Guanghui, CAO Jianguo, ZHANG Jie, et al. Backup roll contour of a SmartCrown tandem cold rolling mill [J]. Journal of Science and Technology Beijing, 2008, 15(3): 357-361. 